\title{
PAIS-NOSSOS QUE ESTÃO NOS CÉUS... E TAMBÉM NA UNIVERSIDADE: O QUE PENSAM OS UNIVERSITÁRIOS?
}

\author{
Jonatas Michel KuCHNIR \\ NÉVIO de CAMPOS \\ Universidade Estadual de Ponta Grossa (UEPG), Ponta Grossa, Paraná, \\ Brasil
}

\begin{abstract}
Resumo: Este artigo objetiva identificar as representações dos estudantes universitários do Curso de Letras sobre a relação entre Estado e Religião, tomando como pano de fundo a proposta de criação da Capela Ecumênica no Campus Uvaranas, aprovada pelo Conselho Universitário da Universidade Estadual de Ponta Grossa e a prática de orações no interior das escolas públicas brasileiras a fim de perceber as posições dos estudantes de Letras. Apoia-se em dados oriundos de questionários aplicados às cinco turmas do curso de Licenciatura em Letras e no conceito de representação de Roger Chartier e Pierre Bourdieu. Ao cruzar as variáveis de idade, de sexo e de religião com as opiniões expressas pelos acadêmicos sobre ter capela em instituição de ensino superior pública e prática de orações em escolas públicas é possível sustentar que os estudantes apresentam uma fronteira tênue entre Religião e Estado.
\end{abstract}

Palavras-chave: Estado e Religião. Práticas de orações em escolas públicas. Capela ecumênica na UEPG. Representações dos estudantes universitários.

INTRODUÇÃO

A relação entre Estado e Religião é o tema deste artigo. É possível identificar facialmente essa relação a partir da opinião pública brasileira, pois, conforme notícia publicada no portal G1 (REIS, 2016), um dia após a destituição da ex-presidenta Dilma Rousseff, entre as expressões mais citadas pelos deputados na votação aparece "Deus" 58 menções nas falas de 50 deputados federais. "Deus derruba a presidenta do país", noticiou o jornal espanhol El País (MARTíN, 2016). Essa associação entre política e religião pode ser observada em outras situações no Brasil, como, por exemplo: "Bancada evangélica cresce e mistura política e religião no Congresso", publicou o Portal UOL (DIP, 2015); "Ministério tira 'identidade de gênero' e 'orientação sexual' da base curricular", informou a Folha de São Paulo (CANCIAN, 2017); "STF decide que escola pública pode promover crença específica em aula de religião", noticiou El País (MARTín, 2017).

Portanto, essas notícias estão no horizonte da opinião pública brasileira. Há uma aproximação intensa entre política e religião. Conforme informações descritas por Lauro Neto, no jornal O Globo (23 mar. 2013, n. p.), o "[...] ensino religioso é obrigatório em 49\% de escolas públicas, contra lei. Em $51 \%$ dos colégios há costume de se fazer orações" (NETO, 2013). Essa fronteira tênue entre Estado e Religião ganhou reverberação na Uni- 
versidade Estadual de Ponta Grossa (UEPG). Em notícia publicada em 10 de agosto de 2011, no portal da Universidade, indica-se que o Conselho Universitário autorizou a construção de uma capela ecumênica no Campus de Uvaranas (MEYER, 2011).

Esse problema é secular na história brasileira. Ganhou contornos mais contundentes a partir da história republicana, quando formalmente houve separação entre Estado e Igreja. Entretanto, a definição jurídica no momento de criação da República não implicou na contínua manutenção desse entendimento legal durante o século $X X$, muito menos implicou na mudança das representações e das práticas no mundo social, conforme identificam inúmeras pesquisas que tratam desse tema como, por exemplo, Luiz Antônio Cunha $(2017,2013)$.

Assim sendo, este artigo objetiva captar as representações dos estudantes universitários do Curso de Letras sobre a relação entre Estado e Religião. O percurso metodológico sustenta-se na produção de dados por meio de questionários. A proposição da criação da Capela Ecumênica na UEPG e a prática recorrente de orações no interior das escolas públicas são o ponto de partida para formulação dos questionários. Para a realização desta pesquisa, aplicamo-nos às cinco turmas dos cursos de Licenciatura em Letras (Português/Inglês Português/Espanhol e Português Francês).

Os dados, oriundos dos questionários, são discutidos a partir do conceito de representação de Roger Chartier e Pierre Bourdieu. Chartier (2011, p. 20) sustenta que "o conceito de representação foi e é um precioso apoio para que se pudessem assinalar e articular [...] as diversas relações que os indivíduos ou os grupos mantêm com o mundo social". Para o historiador francês $(2011$, p. 20), "[...] as operações de classificação e hierarquização produzem as configurações múltiplas mediante as quais se percebe e representa a realidade". Chartier faz alusão à ideia de Pierre Bourdieu que está no livro $A$ distinção. Nesse livro, ao discutir a realidade da representação e a representação da realidade, o sociólogo francês afirma que "[...] a representação que os indivíduos e os grupos exibem inevitavelmente através de suas práticas e propriedades faz parte integrante de sua realidade social" (BOURDIEU, 2008, p. 447). Chartier dialoga com Bourdieu para sustentar o sentido de se estudar as representações:

As lutas de representações são assim entendidas como uma construção do mundo social por meio dos processos de adesão ou rechaço que produzem. Ligam-se estreitamente à incorporação da estrutura social dentro dos indivíduos em forma de representações mentais, e o exercício da dominação, qualquer que seja, graças à violência simbólica. (CHARTIER, 2011, p. 22).

Assim sendo, a narrativa deste artigo busca captar as representações dos estudantes e articulá-las às variáveis - pertencimento a uma religião, faixa-etária, sexo, série do curso, oriundos de escola pública ou privada - a fim de compreender as representações da realidade e a realidade das representações.

\section{CAPELA NA UEPG E ORAÇÕES EM ESCOLAS PÚBLICAS}


KUCHNIR, J. M.; CAMPOS, N.

Em matéria organizada por Lauro Neto, no jornal O Globo (23 mar. 2013, n.p.), observa-se que:

Na maioria das escolas públicas brasileiras, para passar de ano, os alunos têm que rezar. Literalmente. Levantamento feito pelo portal Qedu.org.br a partir de dados do questionário da Prova Brasil 2011, do Ministério da Educação, mostra que em 51\% dos colégios há o costume de se fazer orações ou cantar músicas religiosas. Apesar de contrariar a Lei de Diretrizes e Bases (LDB), segundo a qual o ensino religioso é facultativo, $49 \%$ dos diretores entrevistados admitiram que a presença nas aulas dessa disciplina é obrigatória. (NETO, 2013).

A citação anterior evidencia uma situação recorrente na educação pública brasileira. Esses dados referem-se à Educação Básica, particularmente, ao Ensino Fundamental, em que a escola oferta a disciplina de ensino religioso, embora deva ser facultativa ao estudante.

Essa condição não parece ser uma particularidade das escolas públicas, pois também há, frequentemente, mistura entre a ideia de laicidade e religiosidade no ensino superior, como é o caso da UEPG, Paraná. No extrato da ata 02/2011 do Conselho Universitário, consta o seguinte:

Processo no 10.561/2011 no qual o Pró-Reitor de Planejamento encaminhou proposta para a execução da edificação da Capela Ecumênica no Campus Universitário em Uvaranas desta Universidade; destacou que o relato seria [feito] pelo Conselheiro Altair Justino, que se encontrava em viagem; desta forma, apresentava a presente proposta a qual considerava relevante; informou que a obra estava prevista para ser executada em três etapas, sendo a princípio efetuada a construção de sua estrutura, após o fechamento e por fim a aquisição da mobília; o senhor Presidente colocou que este investimento poderia vir de recursos próprios, no entanto, tencionava-se angariar recursos externos; sobre o assunto, o Conselheiro José Tadeu Teles Lunardi ressaltou que era necessário atender para as questões constitucionais quanto à promoção ou discriminação de qualquer credo religioso; o senhor Presidente respondeu que seriam tomados todos os cuidados, destacando que a construção de uma capela ecumênica era também praticada por outras Instituições [...]. O senhor Presidente esclareceu que esta iniciativa originouse de diversos pedidos da comunidade universitária, visando à criação de um espaço para o desenvolvimento de atividades. O Conselheiro Airton Severino manifestou sua satisfação relativa à proposta em tela, sendo ele, um dos que fizeram esta solicitação; matéria esta que quando colocada em votação resultou aprovada por unanimidade [...]. (UNIVERSIDADE ESTADUAL DE PONTA GROSSA, 2011).

Essas duas situações foram o pano de fundo para produzir e aplicar $\circ$ questionário aos estudantes da UEPG. Em primeiro lugar, é importante indicar que organizamos o conjunto do questionário em dois grandes grupos: 1) perfil dos acadêmicos; 2) opinião dos respondentes. A partir das tabelas e dos gráficos seguintes tratamos dos dados observados nas respostas dos acadêmicos. 
Tabela 1 - Perfis dos entrevistados

\begin{tabular}{|c|c|}
\hline Questões & Porcentagens \\
\hline Idade: & 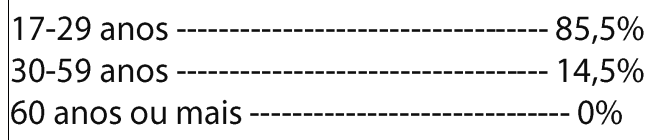 \\
\hline Quanto à religião, você se declara: & 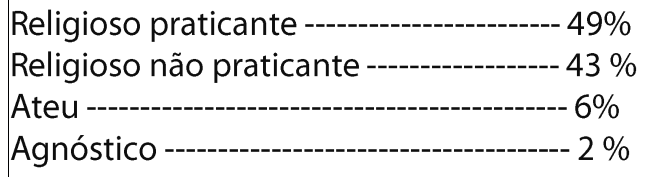 \\
\hline Religião que professa & 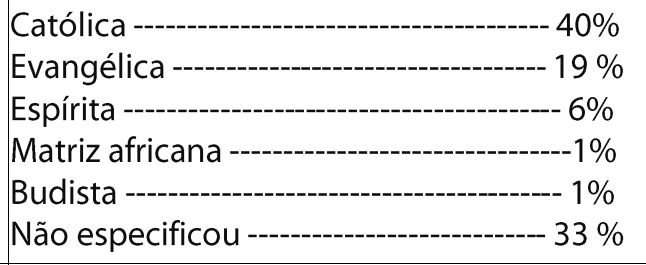 \\
\hline Educação - Ensino Médio: & 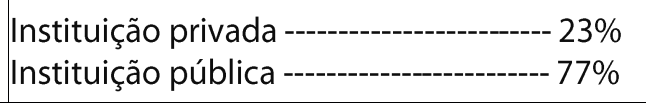 \\
\hline Sexo: & 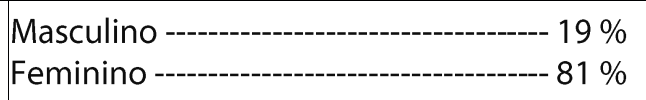 \\
\hline
\end{tabular}

Fonte: Os autores (2017).

No aspecto religioso, notamos que há uma margem pequena (6\%) entre aqueles que se consideram praticantes e não praticantes de uma religião. A porcentagem maior (49\%) é representada por aqueles que se consideram praticantes, ou seja, não só possuem uma religião como realizam seus rituais e demais práticas. Do total, $8 \%$ dos entrevistados consideram-se ateus ou agnósticos.

Em relação à religião professada pelos entrevistados, a parcela maior ficou para os católicos (40\%), seguida dos evangélicos e suas denominações (19\%) e espíritas (6\%). Apenas $1 \%$ do curso declarou-se budista, ao lado de $1 \%$ entre religiões de matriz africana. E 33\% dos acadêmicos não declararam a religião. ${ }^{2}$

Em relação ao sexo, à idade e ao tipo de instituição de educação no Ensino Médio dos entrevistados, é possível dizer que o público é, em sua maioria, feminino (81\%), provindo de escolas públicas (77\%) e entre 27 e 29 anos (85,5\%). Do total, 19\% identificaram-se do sexo masculino, $23 \%$ cursaram o Ensino Médio em escolas privadas e $14,5 \%$ estavam na faixa etária de 30 a 59 anos.

Os questionários permitem também traçar um perfil dos acadêmicos do curso de Letras da Instituição pesquisada. Verificamos uma maioria feminina, entre 17 e 29 anos, provinda de escola pública, praticante de uma religião, mais especificamente, da religião de origem cristã. Dadas essas características gerais do grupo, verificamos como ele se posiciona em relação à construção da Capela Ecumênica na UEPG e sobre a realização de orações nas escolas públicas a fim de estabelecermos relações às características apresen- 
tadas.

Observemos o gráfico que retrata a opinião dos entrevistados a respeito da construção da capela na UEPG.

Gráfico 1 - Opinião dos acadêmicos quanto à construção da capela na UEPG (\%)

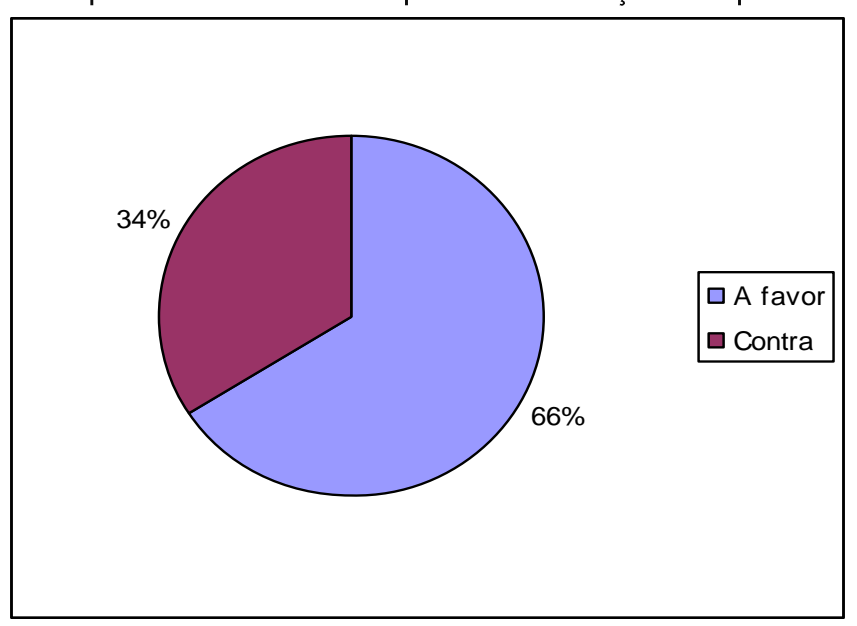

Fonte: Os autores (2017).

Por meio da aplicação dos questionários pudemos verificar que $66 \%$ dos entrevistados posicionam-se favoráveis, e $34 \%$ afirmam-se contrários à construção da capela ecumênica na Instituição. As representações desses sujeitos, portanto, dialogam com diversos discursos das mais diversas esferas nas quais transitam (religiosa, familiar, escolar). Posicionar-se favorável ou contrariamente à construção da capela é assumir determinada visão que vai muito além dizer "sim" ou "não". Essa representação pode ser aproximada da reflexão de Bourdieu (2008, p. 446) de que:

Os sujeitos classificantes que classificam as propriedades e as práticas dos outros, ou as deles próprios, são também classificáveis que se classificam (perante os outros), apropriando-se das práticas e propriedades já classificadas segundo sua repartição provável entre os grupos, eles próprios classificados.

Ao assumir-se favorável à construção religiosa no espaço público, o acadêmico dialoga com discursos religiosos, assumindo-os em maior escala que a ideia de uma separação precisa entre Estado e Religião. A voz da religião, nesse momento, assume lugar de primazia. Além disso, é importante assinalar que a ideia de Estado laico não guarda uma compreensão única. No caso do Brasil, conforme bem explicita Luiz Antônio Cunha (2017, p. 20):

A primeira onda laica atingiu seu ápice com a instituição do regime republicano, que acabou com o padroado, separou a Igreja Católica (e qualquer outra) do Estado, suprimiu os subsídios financeiros ao clero, garantiu liberdade de culto, secularizou os cemitérios públicos e determinou que as escolas públicas fossem laicas, portanto sem a disciplina Ensino Religioso, moral religiosa ou unidades de disciplinas com teor teológico. 
No entanto, após a República, houve grande investimento da Igreja Católica para manter seu ideário atrelado aos princípios republicanos, como atestam diversos estudos, a exemplo de Névio de Campos (2010, 2011). Além disso, segundo observa Cunha (2017, p. 20):

A primeira onda laica levou décadas a se formar, mas seu amortecimento foi rápido, porque uma parte dos protagonistas da laicidade do Estado se satisfez com as conquistas jurídico-políticas expressas na Constituição de 1891 e acionou os freios de segurança para deter o processo em curso; a outra parte não teve forças para levar o processo adiante.

Cunha dialoga com Wenceslau Gonçalves Neto para sustentar que após o regime republicano, "ao invés de rompimento, houvera uma busca de entendimento de ambas as partes, de modo que o Estado continuou contando com as bênçãos católicas e o clero prosseguiu com acesso aos subsídios estatais e outros benefícios" (CUNHA, 2017, p. 24). Ora, essa síntese indica que prevalece uma fronteira bastante tênue e imprecisa entre Estado e Religião, acepção que pode ajudar a compreender as representações dos estudantes que responderam ao questionário desta pesquisa.

O Gráfico 2 traz, em porcentagens, a identidade religiosa dos estudantesparticipantes. Lado a lado, comparamos os dois grupos entre os que praticam alguma religião ou não.

Gráfico 2 - Acadêmicos a favor e contra a construção da capela - praticante ou não praticante de sua religião $(\%)^{3}$

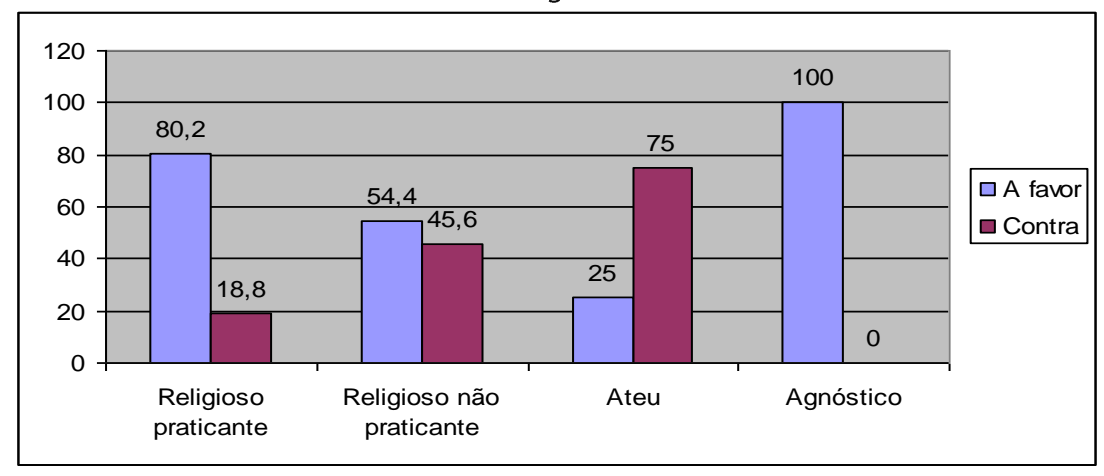

Fonte: Os autores (2017)

Notamos que, entre aqueles que se declararam religiosos praticantes, $80,2 \%$ posicionaram-se favoráveis à construção da capela. Já entre os que se consideraram religiosos não praticantes, essa porcentagem sofreu uma queda $(54,4 \%)$. Entre os ateus, há uma inversão, pois $75 \%$ posicionaram-se contrários à construção. Já 100\% dos agnós- 
ticos entrevistados são favoráveis à construção.

Esses dados indicam que, quanto mais o sujeito circula pelas esferas religiosas, menos compartilha com a ideia de uma fronteira melhor definida entre os interesses do Estado e os interesses religiosos. Por outro lado, é notável que os que se identificaram como ateus, $25 \%$ posicionaram-se favoráveis à existência de uma capela no interior de espaço estatal e público de ensino. Destaca-se, também, que o percentual de declarante agnóstico tem posição favorável à capela na UEPG. Esses dados mostram a complexidade desse problema no Brasil. Não há uma visão clara de laicidade. Ao contrário, prevalece uma noção difusa de que os interesses do Estado estão associados aos imperativos das religiões. No entanto, é importante assinalar que essa relação intrínseca entre Estado e Religião tem a ver com a constituição histórica do Brasil, o que implica em observar as benesses concedidas pelo Estado a algumas religiões, em particular, àquelas que contribuem para legitimar o domínio simbólico do próprio Estado (BOURDIEU, 2014).

Outro fator analisado, em se tratando da circulação dos acadêmicos pelas esferas religiosas, é a vertente religiosa que o acadêmico professa, conforme podemos observar no gráfico a seguir:

Gráfico 3 - Acadêmicos a favor e contra a construção da capela quanto à religião que professam (\%)

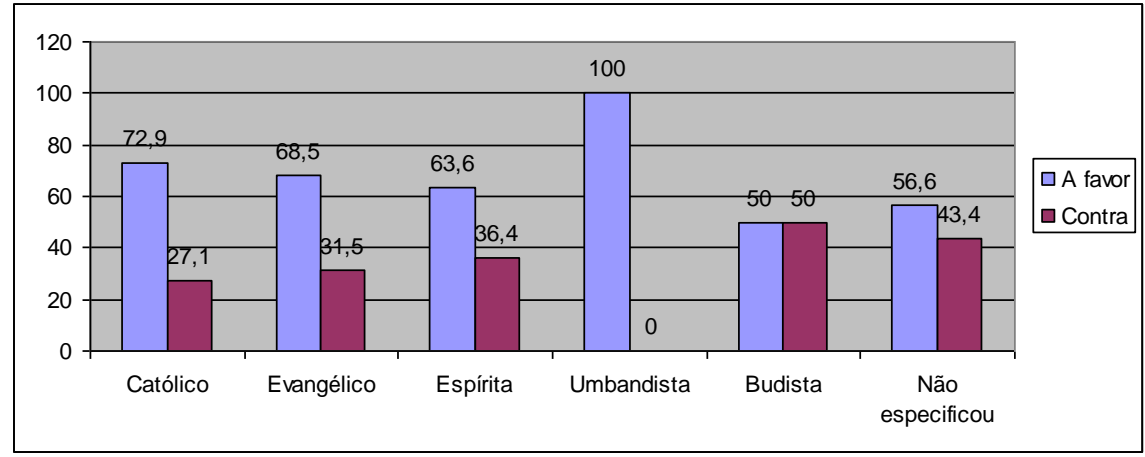

Fonte: Os autores (2017).

Pelos dados, observa-se que $72,9 \%$ dos católicos entrevistados posicionam-se favoráveis à construção da capela ( $27,1 \%$ contrários). Entre os entrevistados das vertentes evangélicas e espíritas, a porcentagem é semelhante, pois $68,5 \%$ são favoráveis entre os evangélicos, $63,3 \%$ entre os espíritas. Entre os umbandistas, $100 \%$ posicionaram-se favoráveis. Já os budistas dividem-se em $50 \%$ favoráveis e $50 \%$ contrários. Por fim, em se tratando daqueles que não especificaram a religião, $56,6 \%$ são favoráveis à edificação do templo religioso da Universidade. De modo geral, os indivíduos de todas as religiões mostraram-se igualmente favoráveis à construção da capela ecumênica na Universidade Pública. Somente entre os budistas o número de indivíduos contrários se aproximou dos favoráveis de outras religiões.

A partir dos dados expostos, é possível sustentar que as representações do que seria Estado laico e suas implicações na organização das diferentes atividades nas esferas estatais são compreendidas de modo difuso entre os entrevistados. Nesse aspecto, estão sintonizadas com as discussões presentes na produção acadêmica, pois, ao refletirmos sobre a questão da laicidade no Brasil, pudemos perceber que as religiões de cunho 
cristão estiveram presentes na constituição do país. Antes mesmo de declarada a laicidade dos espaços públicos, o Estado possuía como religião oficial, a saber, Igreja Católica Romana.

Além do perfil religioso dos entrevistados, outros elementos foram postos em análise, entre eles o período do curso de Letras em que se encontram os acadêmicos. Vejamos:

Gráfico 4- Opinião dos acadêmicos em relação à construção da capela - de acordo com a série (\%)

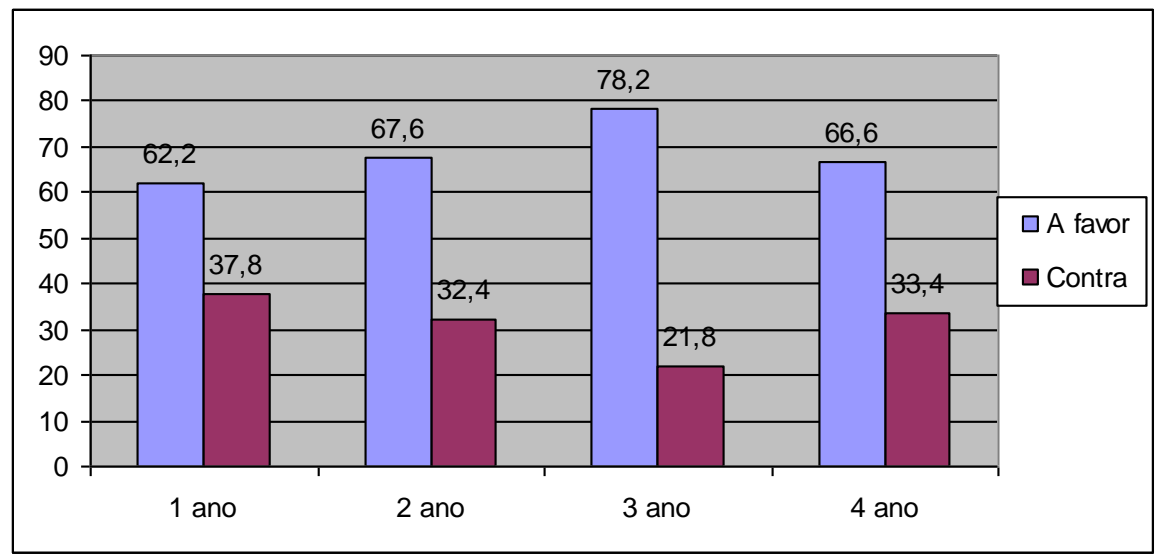

Fonte: Os autores (2017).

Nota-se que $62,2 \%$ dos acadêmicos do primeiro ano do curso posicionaram-se favoráveis à construção da capela. Essa porcentagem aumenta para $67,6 \%$ e 78,2\% entre os alunos do segundo e terceiro anos, respectivamente. No quarto ano do curso, essa porcentagem possui uma leve queda $(66,6 \%)$, mas continua sendo mais elevada que a porcentagem do primeiro ano. Os acadêmicos mostraram-se majoritariamente favoráveis à construção da capela ecumênica, independentemente do período do curso em que se encontram. Essa constatação nos permite concluir que o curso analisado não tem força para construir uma visão mais secular da educação, embora se trate de uma licenciatura.

No último gráfico, observar-se-á a similaridade entre a defesa da construção da capela ecumênica no Campus da UEPG e a realização de orações em escolas públicas. Nas duas primeiras colunas, temos a porcentagem do grupo favorável à construção da capela e sua posição em relação à prática de orações no interior das escolas. Nas duas últimas, os que se posicionaram contrários à capela e suas percepções sobre a prática de orações em escolas públicas. 
Gráfico 5 - Acadêmicos favoráveis e contrários à construção da capela e posição acerca da realização de orações nas escolas públicas $(\%)^{4}$

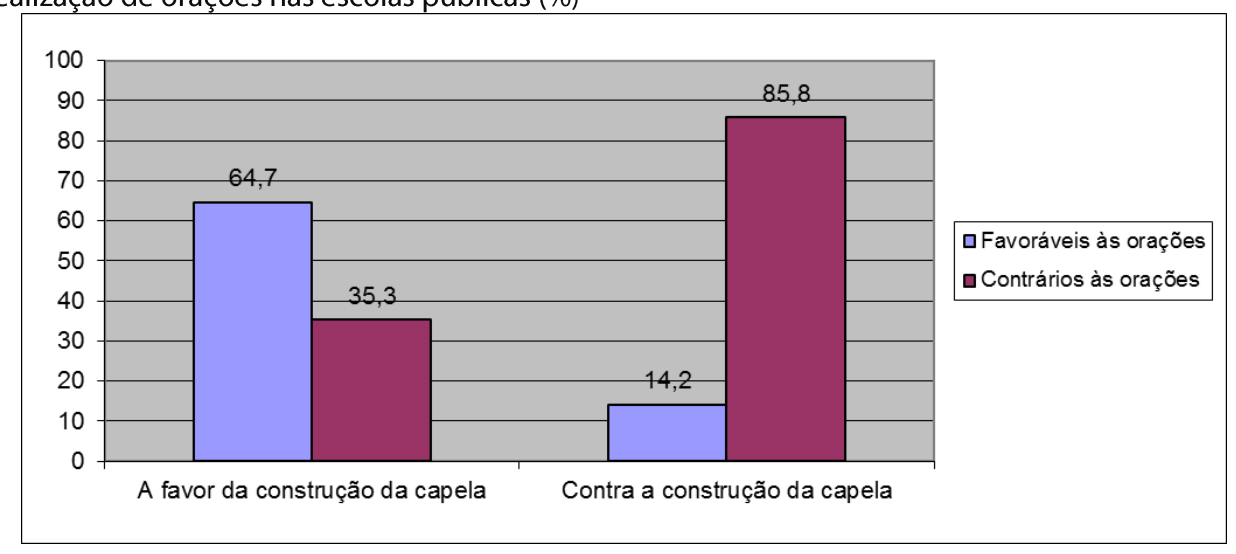

Fonte: Os autores (2017).

Entre os acadêmicos favoráveis à construção da capela, 64,7\% compartilham da ideia de realização de orações nas escolas públicas. Os outros $35,3 \%$, embora favoráveis à capela, são contrários à realização de orações nas escolas públicas. Na segunda coluna, $85,8 \%$ daqueles que são contrários à construção da capela, são também contrários à realização das orações; já 14.2\% são contrários à construção da capela, mas são favoráveis a orações em escolas públicas.

Em regra, os que defendem orações em escolas públicas tendem a aprovar a criação da capela no Campus da UEPG. No entanto, é bastante interessante notar que uma pequena porcentagem aprova a capela e desaprova a existência de orações em escolas públicas. De outro lado, grande parte que se manifestou contrária à construção da capela desaprovou a prática de orações nas escolas públicas. Igualmente, mesmo em porcentagem menor, chama atenção que universitários contrários à capela tenham se posicionado favoráveis a orações nas escolas públicas. Essas disparidades não podem ser explicadas pelos dados oriundos dos questionários, pois requer o uso de outros instrumentos de pesquisa para captar as razões que alguns universitários mobilizam para apresentarem posicionamentos com algum grau de contradição.

Apesar dessas disparidades, torna-se mais claro que o segundo grupo compartilha de uma visão neutra de Estado (BOURDIEU, 2014), embora quase 15\% que dizem ser contrários à criação de uma capela na UEPG defendem a prática de orações em escolas públicas. Igualmente, entre os favoráveis à capela há quem se posicione contrariamente à prática de orações nas escolas públicas (35\%). Observa-se que, no plano das constituições, buscou-se tipificar uma República laica. Entretanto, na própria legislação nota-se uma contínua ambiguidade. De todo modo, se é possível dizer que o Estado professa certa laicidade, o processo de secularização tem baixa reverberação na sociedade brasileira. Em interlocução com Bourdieu (2014), é possível dizer que o modelo de Estado da constituição da República brasileira professava uma visão de Estado como lugar neutro. Porém, as práticas dos governantes são demarcadas por alianças contínuas com religiões com forte poder social, pois, como bem identificam as pesquisas dessa área 
(Campos, 2010; Cunha, 2017), a Igreja ajuda(va) a legitimar o poder do Estado. Nesse sentido, entende-se com mais clareza porque as experiências dos brasileiros são demarcadas por uma tradição não secular, aspecto presente entre os estudantes investigados, inclusive entre aqueles que se identificaram ateus e agnósticos.

As tendências identificadas entre os estudantes guardam relação com as controvérsias da própria história brasileira, pois pensar a laicidade no Brasil não é uma tarefa fácil. Prova disso é analisarmos as relações de poder e disputas em torno da escrita de cada Constituição que regem/regeram nosso país desde o Império. São documentos que norteiam a concepção de Estado em cada período. A religião, por sua vez, está/esteve presente nesse continuum, algumas vezes mais presente, em outras, mais distante, alternando assim a ideia de um Estado deveras laico.

Desse modo, pensar a laicidade é pensar em um Estado que preza pelo respeito às diversidades religiosas sem julgamento de valor e sem enaltecer uma religião em detrimento de outras. É um Estado que permite a realização de cultos religiosos sem que estes interfiram nas decisões políticas do país. "Assim, o caráter laico do Estado, que the permite separar-se e distinguir-se das religiões, oferece à esfera pública e à ordem social a possibilidade de convivência da diversidade e da pluralidade humana" (FISCHMANN, 2012, p. 16).

No âmbito das constituições, essas controvérsias se mostraram presentes. Na primeira Constituição (BRASIL, 2001a), promulgada em 1824, tem-se ainda um Estado Confessional, que trazia a religião Católica Romana como oficial. Antes mesmo da próxima Constituição, logo após a proclamação da República em 1890, Ruy Barbosa redigiu o Decreto 119-A que separou Estado e Igreja Católica Romana.

A Constituição de 1934 (BRASIL, 2001b) dedica um espaço significativo à educação e garante a não distinção perante diferenças religiosas, pois, conforme lê-se no Artigo 113, § 10, "[...]todos são iguais perante a lei. Não haverá privilégios, nem distinções, por motivos de nascimento, sexo, raça, profissões próprias ou dos pais, classe social, riqueza, crenças religiosas ou ideias políticas". Enquanto na Constituição de 1934 fica clara a facultabilidade do Ensino Religioso, a Constituição de 1937 (BRASIL, 2001c) - claramente inspirada na ideia de Estado dos regimes fascistas europeus - traz algumas ambiguidades, embora garanta sua não obrigatoriedade. Entretanto, apesar da não arbitrariedade, o Ensino Religioso acabou por tornar-se compulsório, considerando-se a presença expressiva de escolas confessionais e a hegemonia da religião católica no país (VIEIRA, 2007).

Após a queda da ditadura do Estado Novo (1945), temos a promulgação da Constituição de 1946 (BRASIL, 2001d) que continua a garantir um Estado Laico em seu texto. Na Educação, segundo o Artigo 168, §50, "[...] o Ensino Religioso constitui disciplina dos horários das escolas oficiais, e é de matrícula facultativa e será ministrado de acordo com a confissão religiosa do aluno". Entretanto, Vieira (2007) aponta a impossibilidade de saber se religiões não-católicas puderam penetrar livremente nas escolas oficiais. A Constituição de 1967 (BRASIL, 2001e) se dá no contexto do golpe militar de 1964 e abre espaço para a "colaboração [entre Estado e Igrejas] de interesse político, notadamente nos setores educacionais, assistencial e hospitalar" (Artigo 9, II). A atual Constituição, promulgada em 1988, diferente apenas das Constituições de 1891 e 1937, traz em seu 
preâmbulo invocação da proteção de Deus pelo órgão constituinte (TERAOKA, 2010), mesmo garantindo a laicidade do Estado. O Ensino Religioso permanece facultativo para o Ensino Fundamental, amparado pelo artigo 210, § $1^{\circ}$.

Esses estudos das Constituições brasileiras são relevantes para verificarmos como se deu a relação entre Estado e Religião no (con)texto da lei. Pois, "as cartas magnas são documentos escritos para serem divulgados e incorporados à vida pública; configuramse, portanto, como instrumentos formais de prescrição de regras que contribuíram para a formação de um aparato jurídico no País" (VIEIRA, 2007, p. 306).

Notadamente, a laicidade foi prescrita desde 1890 para reger a vida do país. No entanto, entre a prescrição e a própria experiência há uma série de condicionantes, pois houve forte investimento da Igreja Católica para (re)catolicizar os grupos dirigentes da República, conforme atestam Campos (2010) e Cunha (2017) e o processo de legitimação do Estado republicano contou e conta com a magia do poder simbólico das religiões, em particular das cristãs que respondem por $86,6 \%$ dos brasileiros, conforme atestam os dados do IBGE (2010).

Na prática, essa observação torna-se ainda mais complexa e necessária. Os dados identificados neste artigo estão em correspondência com as evidências de inúmeros estudos que tratam das relações entre Estado e Religião, sobretudo no que tange à educação. Destacamos Fischmann (2009, 2012, 2017), Cruz (2015) e Rocha (2016) para sondarmos algumas pesquisas que apontam as expressões religiosas em escolas públicas após a promulgação da Constituição de 1988. Parece-nos, no entanto, que a questão da laicidade no Brasil vai para além da oferta do Ensino Religioso nas escolas públicas. Vejamos:

Há outras maneiras de ensinar religião e ocupar a escola, ainda que não sustentadas por instrumentos legais como a disciplina em questão. A exposição de símbolos religiosos na sala de diretores, no pátio, a prática de orações realizadas em determinadas situações, missas, bíblias expostas e tantas outras manifestações que privilegiam crenças também são formas de ensinar e colonizar o ambiente escolar. (CRUZ, 2015, p. 94).

Como aponta a autora, além da oferta do Ensino Religioso, temos a presença de inúmeros símbolos cristãos nas escolas e demais edifícios públicos que, em regra, privilegiam a crença cristã. Segundo uma pesquisa publicada em 2013, em O Globo, há o costume de se fazer orações (NETO, 2013), gerando constrangimentos a pessoas de religiões não cristãs, como aponta o depoimento:

A professora manda eu rezar "Ó pai bondoso, livra-nos de todo espírito do mal para quem é da macumba entrar na igreja", porque eu sou do candomblé. Se eu não repetir a oração, ela me manda para a sala da direção. E a diretora diz que a professora tem que ensinar o que ela acha que está certo. Não posso falar, senão, ela disse que vou ser reprovada. (NETO, 2013).

Esse depoimento, publicado também pelo jornal O Globo, é de uma aluna de 13 anos, praticante do candomblé, de uma escola no estado do Rio de Janeiro. Segundo a reportagem, ela diz sofrer discriminação por parte de três professoras evangélicas que tentam convertê-la. Na escola em questão, a problemática perpassa a presença obrigatória na disciplina de Ensino Religioso e intensifica-se no quadro docente de modo 
geral.

Essas discussões evidenciam a complexidade da relação entre Estado e Religião, pois mesmo os debates já seculares e a laicidade presente na Constituição no início da República, a própria legislação posterior indica essa tênue e conflitosa fronteira. No plano das representações e das práticas a separação entre Estado e Religião são mais tênues ainda, pois a recorrência de orações nas escolas, o desejo de criação de uma capela em Campus universitário e aprovação de grande maioria dos estudantes que responderam ao questionário evidenciam a assertiva de o Estado ser laico, mas a sociedade brasileira não ser secularizada.

\section{CONCLUSÃO}

A relação entre Estado e Religião no Brasil é centenária. No Império, essa relação encontrava-se tipificada na própria constituição, pois estava prescrita a existência de uma religião oficial do próprio Estado. A República buscou estabelecer uma regulação jurídica que separava Estado e Religião, resguardando ao ente estatal o dever de garantir a liberdade de crença e o direito de livre criação de religiões no Brasil. Não obstante, nesse percurso centenário da República é possível observar ora a afirmação de Estado laico como garantia dos diferentes credos religiosos, ora a inclusão de elementos confessionais na letra da legislação, pendendo para religiões cristãs que estão associadas à própria história do Brasil (Cunha, 2017).

Essa contínua discussão no plano da legislação evidencia a própria movimentação dos grupos sociais, isto é, das instituições religiosas e dos próprios agentes que ocupam cargos no âmbito das esferas estatais. Observa-se uma linha pouco definida entre os princípios da moralidade privada e os princípios da moralidade pública, pois, de modo recorrente, defende-se a vinculação entre Religião e Estado. No plano das representações e das práticas sociais do cotidiano, essas relações mostram-se bastantes presentes, pois, conforme indicamos, há uma tradição em realizar orações no interior das escolas públicas brasileiras. Essa prática é decorrente da própria naturalização das crenças religiosas, isto é, são tomadas como naturais e espontâneas, portanto, a própria historicidade das crenças religiosas é ignorada. Ou nos termos de Pierre Bourdieu (2014, p. 224), trata-se da força do poder simbólico, "esse poder que se exerce de maneira tão invisível que até nos esquecemos de sua existência e que aqueles que o sofrem são os primeiros a ignorar sua existência já que ele só se exerce por se ignorar sua existência". É a dimensão da "realidade da representação e representação da realidade", conforme explicita Bourdieu (2008, p. 446).

Essa percepção faz-se presente entre os agentes investigados nesta pesquisa, pois a grande maioria não manifestou estranhamento a respeito da autorização do Conselho Universitário para se construir uma capela no Campus Uvaranas da UEPG e sobre a prática recorrente de orações no âmbito das escolas públicas brasileiras. $O$ não estranhamento pode ser interpretado como expressão da naturalização das crenças religiosas, isto é, do não reconhecimento dessas crenças como arbitrário cultural (Bourdieu, 2008; 2014). A vinculação dos respondentes alguma religião de maior tradição e poder (religiões cristãs) mostra maior propensão a defender quase uma fusão entre a 
moralidade privada e a moralidade pública. No entanto, essa variável não é suficiente para explicar as posições dos sujeitos investigados nessa pesquisa, pois entre praticantes de religiões com menor poder (umbandista) há concordância entre a inexistência de fronteira entre Religião e Política. De modo mais emblemático são os dados de que parte de ateus e agnósticos compartilham da assertiva de que práticas religiosas devem se fazer presentes nas esferas do Estado.

Essa observação pode ser aproximada da discussão de Bourdieu a respeito do ato cognitivo que está presente na representação da realidade, pois:

Há atos de conhecimento que não são cognitivos no sentido em que se entende habitualmente. É o caso, por exemplo, do sentido de jogo: um jogador de futebol faz a todo instante atos cognitivos, mas que não são atos de conhecimento - no sentido em que se entende correntemente a teoria do conhecimento. São atos de conhecimento corporal, infraconscientes, infralinguísticos. É o acordo entre essas estruturas cognitivas incorporadas, tornadas completamente inconscientes e as estruturas objetivas que é o verdadeiro fundamento do consenso sobre o sentido do mundo, da crença, da opinião, da doxa. (BOURDIEU, 2014, p. 237).

Em síntese, pode-se dizer que, entre os praticantes e pertencentes a religiões há uma tendência a compreender de modo mais tênue a fronteira entre Religião e Estado. Entre esse grupo, aqueles que figuram nas religiões de maior tradição e poder na história brasileira tendem a defender que o Estado não deve ser laico. Não obstante, a fraca percepção da diferença entre Estado e Religião faz-se presente de modo bastante abrangente entre os brasileiros, o que pode ser compreendido pela acepção de que o Estado é laico, mas a sociedade é pouco secularizada.

Artigo recebido em: $29 / 10 / 2018$

Aprovado para publicação em: 06/04/2019

\section{OUR FATHERS WHO ART IN HEAVENS... AND ALSO IN THE UNIVERSITY: WHAT GOES ON IN} STUDENTS' MIND

ABSTRACT: This article aims at identifying the representations of university students from the Language Course about the relationship between State and Religion. It bases itself on the proposition of constructing an Ecumenical Chapel in the Uvaranas Campus. This was approved by the University Council of the State University of Ponta Grossa as well as having prayers inside Brazilian state schools. This was in order to establish the language students' positions. This study also relies on the data drawn from questionnaires applied to 5 groups from the Language Degree course and on the representation concept of Roger Chartier and Pierre Bourdieu. By comparing variables such as age, sex and religion with the opinions given by the students about having a chapel in a state university and the practice of praying in state schools it is possible to sustain that the students present a tenuous frontier between Religion and State.

KEYWORDS: State and Religion. Practice of praying in state schools. Ecumenical chapel at UEPG; Representations of university students. 


\section{PADRES NUESTROS QUE ESTÁN EN LOS CIELOS... Y TAMBIÉN EN LA UNIVERSIDAD: ¿QUE PIENSAN LOS UNIVERSITARIOS?}

RESUMEN: Este trabajo tiene como objetivo identificar las representaciones de los estudiantes universitarios de la Carrera de Letras sobre la relación entre el Estado y la Religión, tomando como telón de fondo la propuesta de creación de la Capilla Ecuménica en el Campus Uvaranas, aprobada por el Consejo Universitario de la Universidad Estatal de Ponta Grossa y la práctica de oraciones en el interior de las escuelas públicas brasileñas a fin de percibir las posiciones de los estudiantes de Letras. Se apoya en datos provenientes de cuestionarios aplicados a las cinco clases de la carrera de Licenciatura en Letras y en lo concepto de representación de Roger Chartier y Pierre Bourdieu. Al comparar variables de edad, de sexo y de religión con las opiniones expresadas por los académicos sobre tener capilla en institución de enseñanza superior pública y práctica de oraciones en escuelas públicas es possible sustentar que los estudiantes presentan una frontera tenue entre religión y Estad.

PALABRAS CLAVE: Estado y Religión. Prácticas de oraciones en escuelas públicas. Capilla ecuménica en la UEPG. Representaciones de los estudiantes universitarios.

\section{NOTAS}

1) Do total de 443 alunos, 185 estudantes responderam ao questionário. As questões tratavam de informações referentes à sua idade, religião, ao sexo, período do curso, se estudaram em colégio público ou privado no Ensino Médio e como se posicionavam a respeito da proposta de construção da capela ecumênica na UEPG e de orações em escolas públicas. A pretensão desta pesquisa é identificar o que os respondentes pensam sobre a laicidade no contexto brasileiro contemporâneo. Ao cotejar as regras da estatística é possível dizer que o tamanho da amostra está dentro dos parâmetros da amostragem aleatória simples, pois o questionário foi aplicado entre os estudantes, considerando os seguintes aspectos: 1) liberdade para responder ou não responder; 2) participação de estudantes que estavam nas salas no momento de aplicação. Do total de 443 alunos registrados no sistema de matrícula, 185 responderam ao questionário. Segundo a fórmula de cálculo do tamanho mínimo da amostra (BARBETA, 2008, p. 58-59), consideramos " $\mathrm{N}$ " (número total de elementos) - 443 e " $n$ " (número de elementos da amostra) - 185. A resolução dessa fórmula faz-se do seguinte modo: multiplica-se 185 por 443, cujo valor é 79740. Além disso, soma-se 185 com 443 , cujo valor é 628. Por fim, divide-se 79740 por 628 , cujo resultado é 127 . Portanto, o número mínimo de respondentes do questionário deveria ser 127 estudantes. A considerar que 185 estudantes responderam ao questionário, esta pesquisa está dentro do erro amostral tolerável (Eo), isto é, porcentagem de erro tolerável inferior a $4 \%$.

2) Conforme último Censo do IBGE (2010), especificamente a Tabela 1.4.1 - População residente, por situação do domicílio e sexo, segundo os grupos de religião - os 190.755 .799 brasileiros estão assim distribuídos: $123.280 .172(64,6 \%)$ - Igreja Apostólica Romana; 7.686 .827 (18,5\% do total de evangélicos) - Evangélicos de Missão; 25.370 .484 (60\% do total de evangélicos) - Evangélicos de origem pentecostal; 9.218 .129 (21,8\% do total de evangélicos) - Evangélicos de origem não determinada; 3.848 .876 (2\%) - Espíritas; 588.797 (0,3\%) - Umbanda, Candomblé e/ou outras afrobrasileiras; $5.185,065(2,7 \%)$ - outras religiosidades; $15.335 .510(8 \%)$ sem religião. O total de Evangélicos é de $22 \%$ da população brasileira. Esses dados são gerais. A tabela 1.4.1 - População residente, por situação do domicílio e sexo, segundo os grupos de religião - traz os dados referentes 
KUCHNIR, J. M.; CAMPOS, N.

às diferentes religiões existentes no Brasil, inclusive sobre as declaradas pelos estudantes participantes de nossa pesquisa.

3) A declinação das colunas de cor lilás (80,2\% - 54,4\% - 25\%) representa também declinação da circulação desses indivíduos pelas esferas religiosas, logo, da influência desse discurso na constituição identitária desses sujeitos. Observamos nas colunas de cor lilás os acadêmicos que assumiram-se favoráveis à construção da capela e nas colunas de tom tinto aqueles que posicionaram-se contrários.

4) A cor lilás representa aqueles que são favoráveis à realização de orações nas escolas públicas. Em cor vinho, os que contrários à realização dessa prática religiosa.

\section{REFERÊNCIAS}

BARBETA, P. A. Estatística aplicada às Ciências Sociais. Florianópolis: UFSC, 2008.

BRASIL. Constituições Brasileiras. 1891. Brasília: Senado Federal e Ministério da Ciência e Tecnologia, Centro de Estudos Estratégicos, 2001a. (vol. II).

BRASIL. Constituições Brasileiras. 1934. Brasília: Senado Federal e Ministério da Ciência e Tecnologia, Centro de Estudos Estratégicos, 2001b. (vol. III).

BRASIL. Constituições Brasileiras. 1937. Brasília: Senado Federal e Ministério da Ciência e Tecnologia, Centro de Estudos Estratégicos, 2001c. (vol. IV).

BRASIL. Constituições Brasileiras. 1946. vol. V. Brasília: Senado Federal e Ministério da Ciência e Tecnologia, Centro de Estudos Estratégicos, 2001d.

BRASIL. Constituições Brasileiras. 1967. vol. VI. Brasília: Senado Federal e Ministério da Ciência e Tecnologia, Centro de Estudos Estratégicos, 2001e.

BRASIL. Constituições Brasileiras. 1988. vol. VII. Brasília: Senado Federal e Ministério da Ciência e Tecnologia, Centro de Estudos Estratégicos, 2003.

BRASIL. Decreto 119-A, de 09 de janeiro de 1890. Disponível em: <https://www.planalto.gov.br/ccivil_03/decreto/1851-1899/d119-a.htm>. Acesso em: 30 ago. 2017.

BOURDIEU, P. A distinção: crítica social do julgamento. São Paulo: EDUSP; Porto Alegre: ZOUK, 2008.

BOURDIEU, P. Sobre o Estado. Cursos no Collège de France (1989-92). São Paulo: Companhia das Letras, 2014.

CAMPOS, N. Debate sobre ensino religioso na capital paranaense: entre a tribuna e a imprensa (1922-1931). Educação em Revista, v. 27, p. 65-92, 2011. 
CAMPOS, N. Intelectuais e Igreja Católica no Paraná (1926-1938). Ponta Grossa: UEPG, 2010.

CANCIAN, N. Ministério tira 'identidade de gênero' e 'orientação sexual' da base curricular. Folha de São Paulo, 2017. Disponível em: $<$ http://www1.folha.uol.com.br/educacao/2017/04/1873366-ministerio-tira-identidadede-genero-e-orientacao-sexual-da-base-curricular.shtml>. Acesso em: 26 set. 2017.

CHARTIER, R. Defesa e ilustração da noção de representação. Fronteiras, Dourados, MS, v. 13, n. 24, p. 15-29, jul./dez. 2011.

CRUZ, R. B. Educação, Ciência e doutrinas religiosas: relações e representações para as escolas públicas. 2015, 145 f. Dissertação (Mestrado em Educação). Faculdade de Humanas e Direito, Universidade Metodista de São Paulo, São Bernardo do Campo, 2015.

CUNHA, L. A. O sistema nacional de ensino e o ensino religioso nas escolas públicas. Educação e sociedade, Campinas, v. 34, n. 124, p. 925-941, jul./set. 2013. Disponível em: <https://www.redalyc.org/pdf/873/87328534014.pdf>. Acesso em: 25 set. 2018.

CUNHA, L. A. A educação brasileira na primeira onda laica: do Império à República. Rio de Janeiro: Edição do Autor, 2017.

DIP, A. Bancada evangélica cresce e mistura política e religião no Congresso. UOL Notícias. 2015. Disponível em: $<$ https://noticias.uol.com.br/politica/ultimasnoticias/2015/10/19/bancada-evangelicacresce-e-mistura-politica-e-religiao-no-congresso.htm?cmpid=copiaecola $>$. Acesso em: 26 set. 2017.

FISCHMANN, R. Constituição Brasileira, direitos humanos e educação. Revista brasileira de Educação, v.40, p. 156-167, 2009.

FISCHMANN, R. Estado laico, educação, tolerância e cidadania: para uma análise da concordata. São Paulo: Factash Editora, 2012.

FISCHMANN, R. Escolas públicas e ensino religioso subsídios para a reflexão sobre o Estado laico, a escola pública e a proteção do direito à liberdade de crença e de culto. Com Ciência, n. 56. 2004. Disponível em: <http://www.comciencia.br/dossies-172/200407/reportagens/09.shtml $\geq$. Acesso em: 30 ago. 2017.

IBGE. INSTITUTO BRASILEIRO DE GEOGRAFIA E ESTATÍSTICA. Características gerais da população, religião e pessoas com deficiência. Rio de Janeiro: IBGE, 2010. Disponível em: $<$ https://biblioteca.ibge.gov.br/visualizacao/periodicos/94/cd_2010_religiao_deficiencia .pdf>. Acesso em: 05 abr. 2019. 
KUCHNIR, J. M.; CAMPOS, N.

MARTíN, M. STF decide que escola pública pode promover crença específica em aula de religião. El País, 2017.Disponívelem:

$<$ https:/brasil.elpais.com/brasil/2017/08/31/politica/1504132332_350482.htmb. Acesso em: 27 set. 2017.

MARTíN, M. Impeachment Dilma Roussef: Deus Derruba A Presidenta Do Brasil. El País, 2016. Disponívelem:

<https://brasil.elpais.com/brasil/2016/04/18/politica/1460935957_433496.html>. Acesso em: 30 ago. 2017.

MAYER, C. A. Campus de Uvaranas terá capela ecumênica. Portal da UEPG. 2011.

Disponível em: <http://portal.uepg.br/noticias.php?id=1193>. Acesso em: 28 jul. 2017.

NETO, L. Ensino religioso é obrigatório em 49\% de escolas públicas, contra lei. 2013. Disponível em: <https://oglobo.globo.com/sociedade/educacao/ensino-religiosoobrigatorio-em-49-de-escolas-publicas-contra-lei-7928028\#ixzz4nNiTAZmE>. Acesso em: 01 ago. 2017.

REIS, T. Deus, filhos... Veja os termos mais citados na votação do impeachment. G1, 2016. Disponível em: <http://g1.globo.com/politica/processo-de-impeachment-dedilma/noticia/2016/04/deus-filhos-veja-os-termos-mais-citados-na-votacao-doimpeachment.html>. Acesso em: 30 ago. 2017.

ROCHA, M. Z. B. Expressões religiosas em escolas públicas: representações sociais ou ideologia? Acta Scientiarum, Maringá, v. 38, n. 3, p. 231-246, 2016.

TERAOKA, T. M. C. A Liberdade Religiosa no Direito Constitucional Brasileiro. 2010, $282 \mathrm{f}$. Tese (Doutorado em Direito) - Faculdade de Direito, Universidade de São Paulo, São Paulo, 2010.

UNIVERSIDADE ESTADUAL DE PONTA GROSSA. Secretaria Geral dos Conselhos Superiores. Extrato da ata no 02/2011. p. 1-2, 2011.

VIEIRA, S. L. A educação nas constituições brasileiras: texto e contexto. Revista Brasileira de Estudos Pedagógicos, Brasília, v. 88, n. 219, p. 291-309, 2007. 
Jonatas Michel KuChnir: Mestrando em Estudos da Linguagem na Universidade Estadual de Ponta Grossa. Graduação em Letras Francês pela mesma Universidade.

ORCID: https://orcid.org/0000-0002-5298-1790

E-mail: jonatas_michel@live.com

NéVIO de Campos: Pós-Doutor em História. Doutor em Educação. Professor no Programa de Pós-Graduação em Educação e no Programa de Mestrado em História da Universidade Estadual de Ponta Grossa, Paraná. Pesquisador Produtividade CNPa 2.

ORCID: https://orcid.org/0000-0003-1850-316X

E-mail:ndoutorado@yahoo.com.br

Este periódico utiliza a licença Creative Commons Attribution 3.0, para periódicos de acesso aberto (Open Archives Iniciative - OAI). 